\title{
Molecular dynamics simulation of water molecules absorption by different cations based Montmorillonite
}

\author{
Honghua Zhao ${ }^{\text {i) }}$, Cong Liu ${ }^{\text {ii) }}$ and Shuqi Jiang ${ }^{\text {iii) }}$, Yuanyuan $\mathrm{Ge}^{\mathrm{iv})}$ \\ i) Associate Professor, State Key Laboratory of Structural Analysis for Industrial Equipment, Department of Engineering \\ Mechanics, Dalian University of Technology, Dalian 116023, China. \\ ii) Ph.D Student, Geotechnical Research Institute, Dalian University of Technology, Dalian 116023, China. \\ iii) Ph.D Student, State Key Laboratory of Structural Analysis for Industrial Equipment, Department of Engineering \\ Mechanics, Dalian University of Technology, Dalian 116023, China. \\ iv) Research Assistant, State Key Laboratory of Structural Analysis for Industrial Equipment, Department of Engineering \\ Mechanics, Dalian University of Technology, Dalian 116023, China.
}

\begin{abstract}
Using molecular mechanics and molecular dynamics (MD) methods, Li-, Na-, K-, Ca- cations based montmorillonite models are built in materials studio software. Molecular dynamic simulations are carried out to investigate the influences of different cations on the swelling behavior of montmorillonite when absorbing water. Molecular dynamic simulations indicate that the montmorillonite's volume and layer spacing are increased by multi-steps, but the density is reduced by multi-steps. Water molecule concentration profiles in lithium-, sodium-, potassium- and calcium-montmorillonite adsorption models show that the montmorillonite can form one, two and three layers of water molecules. The radial distribution function of Li-, Na-, K-, Ca- cations based montmorillonite is obtained for absorbing 16 to 96 water molecules. The results indicate $\mathrm{Li}+$ is easier to hydrate, follows by Na+, while $\mathrm{K}+$ and $\mathrm{Ca} 2+$ are not easy to hydrate. Different types of cations between layers have different effects on the adsorption ability of montmorillonite.
\end{abstract}

Keywords: Montmorillonite, cations, water molecules, MD simulation

\section{INTRODUCTION}

Montmorillonite is a dominant clay mineral in expansive soil. It has the physicochemical properties of adsorption, cation exchangeability, water absorption and expansion. Many studies have been carryout out on its structure and properties (Zhuang 2015, Bishop 2002, Luckham 1999, Van Geet 2007). In addition, expansive soil can cause series engineering problems due to swelling and shrinkage of montmorillonite (Abduljauwad 2000, Yin 2012). Researchers in geotechnical community have carried outs a plenty of investigations on montmorillonite (Sun 2016, Qi 2016). Montmorillonite is a typical clay mineral, Dioctahedral silicate, structural layer 2:1 type, crystal structure formulae is $\mathrm{M}_{x}\left(\mathrm{H}_{2} \mathrm{O}\right)_{n}\left\{\left(\mathrm{Al}_{2-x} \mathrm{Mg}_{x}\right)\left[(\mathrm{SiAl})_{4} \mathrm{O}_{10}\right](\mathrm{OH})_{2}\right\}, M$ represents interlayer exchange cations, mainly calcium or sodium ions, can also be lithium ion or potassium ions( $\mathrm{Na}, 2006)$.

At present, a large number of applications have been obtained for numerical simulation of microscopic and micromechanics of materials at molecular scales. Molecular simulation methods include two kinds of simulation methods, one based on quantum mechanics, including density functional theory, ab initio method, the semi-empirical method, and the other based on classical mechanics, including Brownian dynamics, molecular dynamics methods, molecular mechanics methods, Monte Carlo methods (Chang 1995,1997, 1998). Many scholars have also carried out molecular simulation research on the water absorption characteristics of montmorillonite (Skipper 1995, Boek 1995, Young 2000, Bathija 2009).

In this study, Li-, Na-, K-, Ca- Montmorrilonite models are built in material studio. Molecular dynamics simulation of water absorption by them are carried out. The influence of geometry optimization on structure of montmorillonite is also analyzed. The relations of volume, density and layer spacing and water content are obtained by MD simulations. Concentration profiles of cations and water molecules are obtained, as well as their radial distribution function. The influences of cations between layers on water sorption are established. Using the mean square displacement of cations and water molecules in lithium-, sodium-, potassium, calcium-montmorillonite, the self-diffusion coefficient was determined, and the influence of cationic species on the diffusion of interlayer cations and water 
molecules was analyzed. This research is going to help people to get known more about the swelling mechanism of expansive soil and their behavior.

\section{MD MODEL OF MONTMORILLONITE}

Montmorillonite modeling can choose single oblique crystal system c $2 / \mathrm{m}$ space group, symmetrical type of L2PC, lattice constant $\alpha=90^{\circ}, \beta=99^{\circ}, \gamma=90$ $\mathrm{o}, \mathrm{a} \approx 5.23 \AA, \mathrm{b} \approx 9.06 \AA$, when the water molecule is not adsorbed, $c \approx 9.60 \AA$, with one layer of water molecules, $c$ $\approx 12.5 \AA$, with two layers of water molecules, $\mathrm{c} \approx 15.5 \AA$, with three layers of water molecules, $c \approx 18.5 \AA$.

In this paper, the molecular model of montmorillonite is constructed in materials Studio software, First, lithium-, sodium-, potassium-, calcium-montmorillonite monocrystalline cells were constructed. Single-crystal cell ball-stick model and polyhedron stacking model are shown in Figure 1 (a), (b). Then it is extended on the basis of single crystal cell model to complete the construction of the supercell model. The super-cell model containing one valence cations between layers is shown in Figure 2 (a), the interlayer containing divalent cationic ions is shown in Figure 2 (b). Modeling supercell model is using three dimensional periodic boundary conditions. The force filed in the model is using UFF force potential function(Rappe 1992). Van der Waals action can be described by Lennard-Jones potential function (Lennard-Jones 1924). The truncation distance of short-range interaction is $12.5 \AA$.

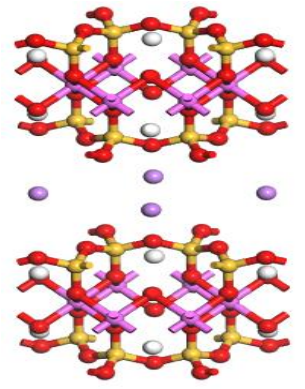

(a)

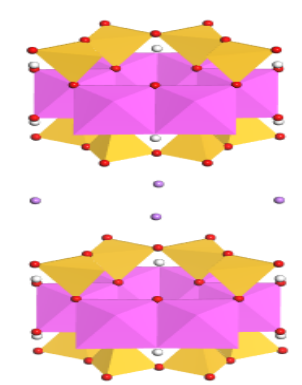

(b)
Fig. 1 Single cell model of Montmorrilonite (yellow: Si, red: O, pink: Al, white: $\mathrm{H}$, purple: $\mathrm{M}+$ ) (a) ball-stick model, (b) polyhedron stacking model

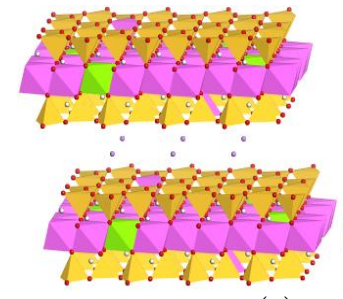

(a)

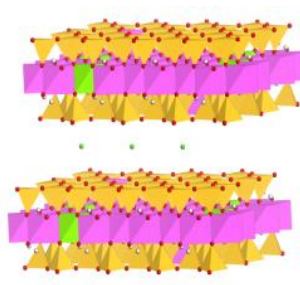

(b)
Fig. 2 Supercell Montmorillonite model (a) one valence cation, (b) two valences cation
Then, using the Sorption module in MS, one layer, two layers and three layers of water molecules are adsorbed in the middle of the Montmorillonite respectively. Flexible SPC model is used for water molecules.

Figure 3 (a) (b) (c) is a montmorillonite structure when adsorption of one layer, two layers and three layers of water molecules, respectively.

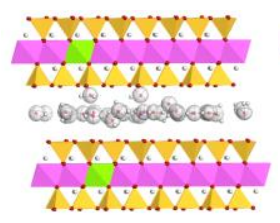

(a)

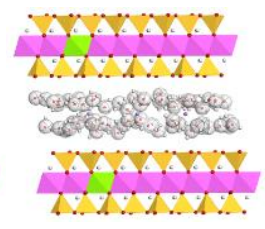

(b)

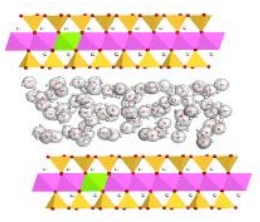

(c)
Fig. 3 Water adsorption model of Montmorillonite: (a) one- layer water molecules, (b) two-layer water molecules, (c) three-layer water molecules.

\section{MD SIMULAITON OF WATER ADSOPRTION BY MONTMORRILONITE}

After the molecular configuration optimization, the Dynamics module in Forcite is used to simulate the process of water absorption of montmorillonite. Using NVE ensemble, the temperature is set to $298 \mathrm{~K}$, the time step is $1.0 \mathrm{fs}$, and the total simulation time is $500 \mathrm{ps}$.

\subsection{Water molecular concentration profile}

The concentration distribution of water molecules along the $\mathrm{z}$ axis in the adsorption model of $\mathrm{Li}^{-}, \mathrm{Na}-, \mathrm{K}-$, Ca-Montmorillonite was observed from the MD simulation results. Only Ca-Montmorillonite was shown here. The concentration distribution of water molecules along the $\mathrm{z}$ axis in the $\mathrm{Ca}$ - Montmorillonite adsorption model is shown in Figure 4. Figure 4 shows that when Ca-Montmorillonite absorbs 32 water molecules, there is a peak appearing along the $\mathrm{z}$-axis for the concentration of water molecule, indicating that water molecules are concentrated in the center of the layer and can be regarded as a layer of water molecules. When Montmorillonite absorbs 64 water molecules, the main peak splits into two basically symmetrical peaks, and the peak value drops, indicating that the water molecules move from the center of the layer to the upper and lower layers and become dispersed, corresponding to the distribution of two layers of water molecules. Still there are some water molecules associated with cations in the middle of the layer as indicated by a small peak. Figure 4 shows that when Montmorillonite absorbs 96 water molecules, there are three peaks in the concentration of water molecules along the $\mathrm{z}$ axis, water molecules become more dispersed and symmetrically distributed between the upper and lower layers, corresponding to the distribution of 3 layers of water molecules. Water molecules attracted by cations and by upper and lower 
layers almost equally. The results of this study verify the characteristics of the swelling of montmorillonite and show that the absorbed water molecules have the characteristics of layered arrangement in the middle of the Montmorillonite layer.

\subsection{Layer spacing, volume, lattice constant $\beta$}

With further analysis of the simulation results, the variation of the spacing, volume, and lattice constant $\beta$ of Montmorillonite layers can be obtained. The relationship between the spacing, volume, and lattice constants of Li-, Na-, K-, Ca-montmorillonite layer and the number of adsorbed water molecules is shown in Figure 5. From Fig. 5, it is shown that the spacing of Li-, Na-, K-, Ca-montmorillonite increases with the increase of the number of adsorbed water molecules, all have a step growth trend. The trend of increasing with time is faster when absorbing 0-16, 32-48 and 80-96 water molecules, while slows down when absorbing 16-32 water molecules, even reduces when absorbing 32 water molecules, which means the first layer of water molecules is about to fill. Adsorption of more than 32 water molecules, the trend of increasing layer spacing is accelerated, but slows down during adsorption of $48-80$ water molecules, this is related to the aggregation of water molecules and the formation of two layers of water molecular layers, while also beginning to adsorb the third layer of water molecules. The increasing trend of layer spacing when absorbing 80-96 water molecules increased slightly, which indicated that the three layers of water molecular layer tend to form.

By observing the relationship between the volume of Li-, Na-, K-, Ca-montmorillonite and the number of adsorbed water molecules, we know that their volume change is similar to that of layer spacing.

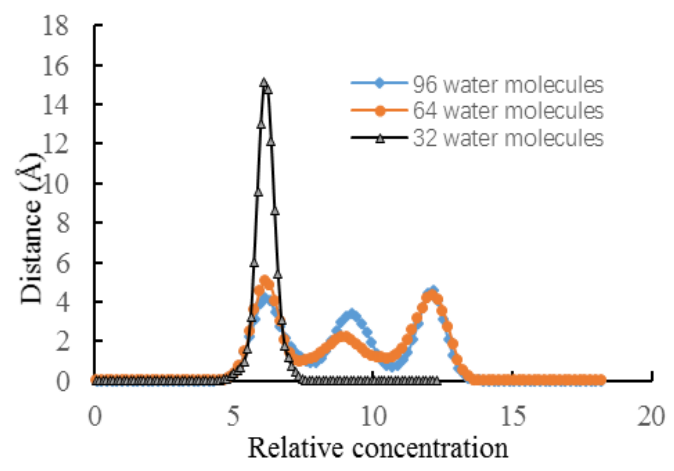

Fig. 4 Water concentration along $\mathrm{z}$ axis.

The changes of the internal components and stress state of the crystal are verified by the disordered change of lattice constant $\beta$ for $\mathrm{Li}_{-}, \mathrm{Na}-, \mathrm{K}-$, Ca-Montmorillonite with the adsorption water molecules. The lattice constant $\beta$ represents the angle between the $z$ axis and the $x$-axis, and $\beta$ change indicates that along the $\mathrm{z}$ axis, as the number of adsorbed water molecules changes, the position of the $\mathrm{z}$ axis changes, and the crystal layer is panned or staggered along parallel to the XY surface. This change is not monotonic, there is no rule to follow.

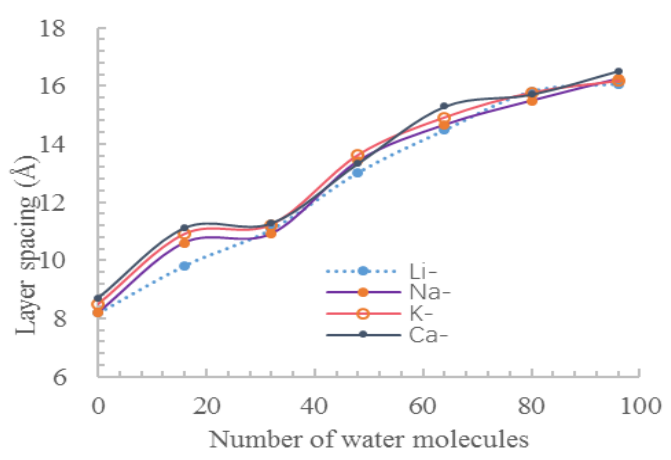

(a) Layer spacing

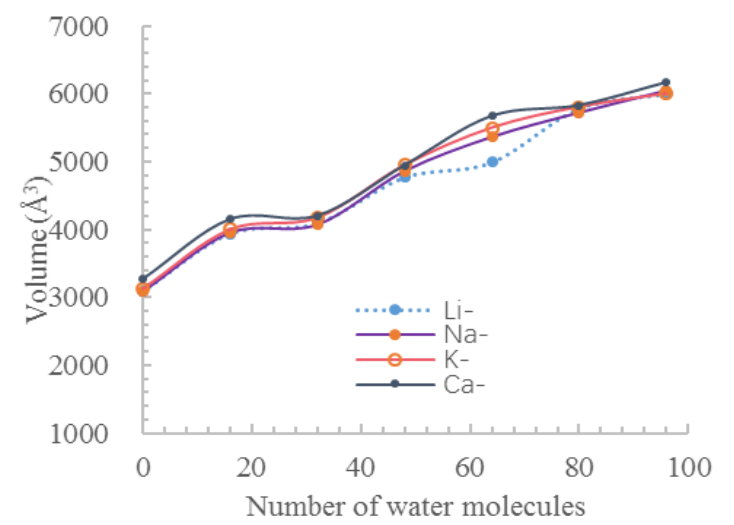

(b) Volume

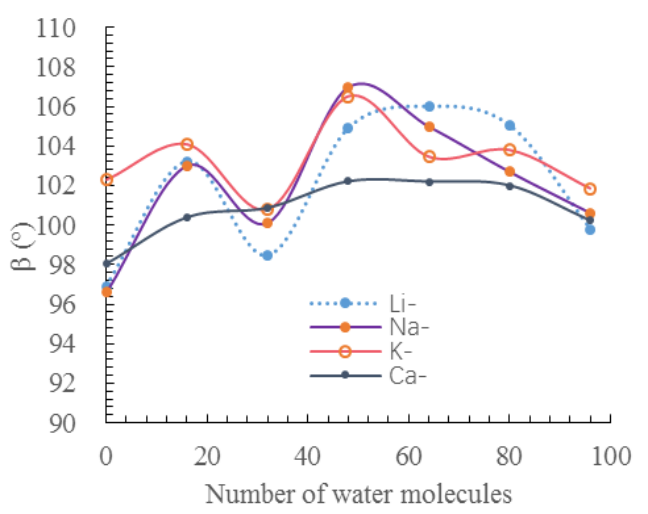

(c) $\beta$

Fig. 5 Lattice constant changes during water adsorption (a) layer spacing, (b)volume, (c) $\beta$.

\subsection{Radial distribution function(RDF)}

Radial distribution function (RDF) represents the probability density of another atom appearing from one atom at a radial distance $\mathrm{R}$. It can be used both to study material order and to describe correlations. Radial distribution functions are usually represented by $g(R)$.

$$
g(r)=\frac{n}{4 \pi \rho r^{2} d r}
$$

where $n$ represents the number of $\mathrm{B}$ atoms within a $r$ to $r+d r$ spherical shell from atom A, $\rho$ is the density of $\mathrm{B}$ 
atoms. The RDF curve can be obtained by using analysis-radial distribution function in the Forcite module in materials Studio software, by sorting out the peak value of the RDF graph curve, the RDF peak $g(r)$ and the corresponding radius $r$ of $\mathrm{Li}^{-}, \mathrm{Na}-, \mathrm{K}-$, Ca-Montmorillonite are obtained, as shown in Table 1.

According to Table 1, from the radial distribution function of $\mathrm{M}^{n+}-\mathrm{O}$, the main peak of the $\mathrm{Li}-\mathrm{O}$ in one-layer hydrate is $1.96 \AA$, the main peak of the Na-O is at $2.20 \AA$, the main peak of $\mathrm{K}-\mathrm{O}$ is $2.52 \AA$, the main peak of $\mathrm{Ca}-\mathrm{O}$ is $2.52 \AA$. For two-layer, three-layer hydrate, the main peak of $\mathrm{Li}-\mathrm{O}$ at $2.04 \AA$, Na-O at 2.28 $\AA$, K-O at $2.60 \AA$, Ca-O at $2.60 \AA$. Observing the radial distribution function of $M^{n+}-H$, we know that the main peak of $\mathrm{Li}-\mathrm{H}$ in one-layer hydrate is $2.68 \AA$, the main peak of $\mathrm{Na}-\mathrm{H}$ is $2.84 \AA$, the main peak of $\mathrm{K}-\mathrm{H}$ is $3.00 \AA$, and the main peak of $\mathrm{Ca}-\mathrm{H}$ is $3.08 \AA$. For two-layer hydrate, Li-H in two-layer hydrate is $2.72 \AA$, the main peak of $\mathrm{Na}-\mathrm{H}$ is $2.92 \AA$, the main peak of $\mathrm{K}-\mathrm{H}$ is $3.16 \AA$, and the main peak of $\mathrm{Ca}-\mathrm{H}$ is $3.16 \AA$. For three-layer hydrate, the main peak of $\mathrm{Li}-\mathrm{H}$ is $2.76 \AA$, the main peak of $\mathrm{Na}-\mathrm{H}$ is $2.92 \AA$, the main peak of $\mathrm{K}-\mathrm{H}$ is $3.24 \AA$, and the main peak of $\mathrm{Ca}-\mathrm{H}$ is $3.24 \AA$.

From the above results, the following conclusions can be obtained: in Li-, Na-, K-, Ca-montmorillonite, $\mathrm{Li}+$ is most likely to organize oxygen atoms and hydrogen atoms, the second is $\mathrm{Na}+\mathrm{K}+$ and $\mathrm{Ca} 2+$ are not easy to organize oxygen atoms and hydrogen atoms. This shows that $\mathrm{Li}+$ is easier to hydrate, while $\mathrm{Na}+$ is the second, $\mathrm{K}+$ and $\mathrm{Ca} 2+$ are not easy to hydrate.

This is due to the smallest ionic radius of the $\mathrm{Li}$ Atom and the strongest metal bond, making it the most hydrated. The radius size order of the four metal ions is $\mathrm{Li}+<\mathrm{Na}+<\mathrm{K}+<\mathrm{Ca} 2+$. The hydration capacity is arranged in reverse order (Zhao 1980). The simulation results of molecular dynamics are reasonable and reflect this correctly.

For the hydrate of Li-, Na-, K-, Ca- montmorillonite, the main peak of $\mathrm{O}-\mathrm{O}$ radial distribution function in the first and two or three layers of hydrate is between 2.60 $\AA$ and $2.68 \AA$, but the peak size is different. A large peak indicates a greater probability of an atom appearing. It shows that the distribution probability of other $\mathrm{O}$ atoms around $\mathrm{O}$ atom in different cationic montmorillonite is different.

For the hydrate of Li-, Na-, K-, Camontmorillonite, the main peaks of $\mathrm{O}-\mathrm{H}$ radial distribution function in the first and two or three layers of hydrate are at $1.00 \AA$, the second peaks are around $2.60 \AA$, but the peak size is different. The main peak represents the probability of distribution of hydrogen atoms combined with $\mathrm{O}$ in the same water molecule, and the second peak represents the probability of distribution of hydrogen atoms in adjacent water molecules. The difference of peak size indicates that the presence of different cations between montmorillonite layers will have a certain effect on the structure of water and the distribution of water molecules.

Table 1. Peak of RDF and its corresponding radius

\begin{tabular}{|c|c|c|c|c|c|c|c|c|c|c|}
\hline \multirow{4}{*}{$\begin{array}{c}\text { Number of } \\
\text { absorted } \\
\mathrm{H} 2 \mathrm{O}\end{array}$} & \multicolumn{10}{|c|}{ Peak of RDF of Li-Monrmorillonite and $r(\AA)$} \\
\hline & \multirow{2}{*}{\multicolumn{2}{|c|}{$\begin{array}{c}\text { Li-O } \\
\text { Main peak }\end{array}$}} & \multirow{2}{*}{\multicolumn{2}{|c|}{$\begin{array}{c}\text { Li-H } \\
\text { Main peak }\end{array}$}} & \multirow{2}{*}{\multicolumn{2}{|c|}{$\begin{array}{c}\mathrm{O}-\mathrm{O} \\
\text { Main peak }\end{array}$}} & \multicolumn{4}{|c|}{$\mathrm{O}-\mathrm{H}$} \\
\hline & & & & & & & \multicolumn{2}{|c|}{ Main peak } & \multicolumn{2}{|c|}{ Second peal } \\
\hline & $\mathrm{r}$ & $g(r)$ & $\mathrm{r}$ & $\mathrm{g}(\mathrm{r})$ & $\mathrm{r}$ & $\mathrm{g}(\mathrm{r})$ & $\mathrm{r}$ & $\mathrm{g}(\mathrm{r})$ & $\mathrm{r}$ & $g(r)$ \\
\hline 16 & 1.88 & 8.88 & 2.6 & 13.6 & 2.68 & 4.7 & 1 & 11.8 & 2.6 & 10 \\
\hline 32 & 1.96 & 12.6 & 2.68 & 17.7 & 2.68 & 4.1 & & & 6 & 43 \\
\hline 48 & 96 & 12 & 2.76 & 14.6 & 68 & 4.1 & & 16 & 6 & 25 \\
\hline 64 & 04 & 14 & 2.76 & 9.94 & 2.68 & 3.9 & & & 6 & .12 \\
\hline 80 & 04 & 18.6 & 2.76 & 15.1 & 2.68 & 3.8 & 1 & & 6 & .74 \\
\hline 96 & 04 & 14.9 & 2.76 & 9.91 & 2.68 & 3.5 & 1 & 18.5 & 2.6 & 14 \\
\hline \multirow{4}{*}{$\begin{array}{c}\text { Number of } \\
\text { absorted } \\
\text { H2O }\end{array}$} & \multicolumn{10}{|c|}{ Peak of RDF of Na-Monrmorillonite and $r(\AA)$} \\
\hline & \multirow{2}{*}{\multicolumn{2}{|c|}{$\begin{array}{c}\mathrm{Na}-\mathrm{O} \\
\text { Main peak }\end{array}$}} & \multirow{2}{*}{\multicolumn{2}{|c|}{$\begin{array}{c}\text { Na-H } \\
\text { Main peak }\end{array}$}} & \multicolumn{2}{|c|}{$\mathrm{O}-\mathrm{O}$} & \multicolumn{4}{|c|}{$\mathrm{O}-\mathrm{H}$} \\
\hline & & & & & \multicolumn{2}{|c|}{ Main peak } & \multicolumn{2}{|c|}{ Main peak } & \multicolumn{2}{|c|}{ Second peak } \\
\hline & $\mathrm{r}$ & $g(r)$ & $\mathrm{r}$ & & $\mathrm{r}$ & $g(r)$ & $\mathrm{r}$ & $g(r)$ & $\mathrm{r}$ & $g(r)$ \\
\hline 16 & 2.12 & 7.71 & 2.84 & 14 & 2.6 & 4.5 & & 11.8 & 2.5 & 10 \\
\hline 32 & 2.2 & 8.09 & 2.84 & 7.81 & 2.68 & 3.9 & & 13.6 & 2.5 & 6.4 \\
\hline 48 & & 13.2 & 2.92 & 14.8 & 2.68 & 4.2 & & 5.4 & 2.6 & 5.35 \\
\hline 64 & 28 & 12 & 2.92 & 13.7 & 2.6 & 3.9 & 1 & 7.7 & 2.6 & 43 \\
\hline 80 & 28 & 13.4 & 2.92 & 11.6 & 2.6 & 3.7 & 1 & 8.3 & 2.7 & .71 \\
\hline 96 & 28 & 18.1 & 2.92 & 12.1 & 2.68 & 3.6 & 1 & 18.9 & 2.7 & 3.17 \\
\hline \multirow{4}{*}{$\begin{array}{c}\text { Number of } \\
\text { absorted } \\
\mathrm{H} 2 \mathrm{O}\end{array}$} & \multicolumn{10}{|c|}{ Peak of RDF of K-Monrmorillonite and $\mathrm{r}(\AA)$} \\
\hline & \multirow{2}{*}{\multicolumn{2}{|c|}{$\frac{\text { K-O }}{\text { Main peak }}$}} & \multicolumn{2}{|c|}{ K-H } & \multicolumn{2}{|c|}{0} & & & $\mathrm{O}-\mathrm{H}$ & \\
\hline & & & Main & peak & Mair & peak & Ma & n peak & $\operatorname{Sec}$ & nd peak \\
\hline & $\mathrm{r}$ & $g(r)$ & $\mathrm{r}$ & $g(r)$ & $\mathrm{r}$ & $g(r)$ & $\mathrm{r}$ & $g(r)$ & $\mathrm{r}$ & $g(r)$ \\
\hline 16 & 2.52 & 5.03 & 3 & 6.92 & 2.68 & 4.6 & 1 & 12 & 2.5 & 10.2 \\
\hline 32 & 2.52 & 7.3 & 3 & 7.85 & 2.68 & 4 & 1 & 13.9 & 2.5 & 6.57 \\
\hline 48 & 2.6 & 7.58 & 3.16 & 8.99 & 2.6 & 4.3 & 1 & 16.7 & 2.5 & .45 \\
\hline 64 & 2.6 & 12.6 & 3.16 & 9.22 & 2.68 & 4 & 1 & 18.1 & 2.5 & 4.54 \\
\hline 80 & 2.6 & 12 & 3.24 & 11.5 & 2.6 & 3.8 & 1 & 18.6 & 2.5 & 3.76 \\
\hline 96 & 2.6 & 9.61 & 3.24 & 8.89 & 2.6 & 3.5 & 1 & 18.5 & 2.5 & 3.14 \\
\hline & & & ak of $R$ & $\mathrm{DF}$ of & $a-M$ & nrmor & 11 & & (A) & \\
\hline & & I-O & $\mathrm{Ca}$ & $\mathrm{a}-\mathrm{H}$ & & & & & $\mathrm{O}-\mathrm{H}$ & \\
\hline & Mair & peak & Main & 1 peak & Mair & peak & $\mathrm{Ma}$ & n peak & $\mathrm{Sec}$ & nd peak \\
\hline & $\mathrm{r}$ & $\mathrm{g}(\mathrm{r})$ & $\mathrm{r}$ & $\mathrm{g}(\mathrm{r})$ & $r$ & $\mathrm{~g}(\mathrm{r})$ & $\mathrm{r}$ & $\mathrm{g}(\mathrm{r})$ & $r$ & $\mathrm{~g}(\mathrm{r})$ \\
\hline 16 & 2.52 & 9.37 & 3.24 & 12.3 & 2.6 & 7.1 & 1 & 12.4 & 2.6 & 10.5 \\
\hline 32 & 2.52 & 8.81 & 3.08 & 7.64 & 2.6 & 6.1 & 1 & 14 & 2.6 & 6.6 \\
\hline 48 & 2.6 & 10.1 & 3.24 & 11 & 2.6 & 6.7 & 1 & 16.6 & 2.6 & 5.44 \\
\hline 64 & 2.6 & 15.2 & 3.16 & 10.7 & 2.6 & 6.5 & 1 & 18.7 & 2.6 & 4.68 \\
\hline 80 & 2.6 & 10.5 & 3.16 & 8.06 & 2.6 & 6 & 1 & 18.6 & 2.6 & 3.77 \\
\hline 96 & 2.6 & 12.6 & 3.24 & 9.56 & 2.6 & 5.8 & 1 & 19 & 2.6 & 3.23 \\
\hline
\end{tabular}

\section{CONCLUSIONS}

Using Materials Studio software, a series of molecular dynamics simulations of Montmorillonite with $\mathrm{Li}+, \mathrm{Na}+, \mathrm{K}+$ and $\mathrm{Ca} 2+$ four different cationic at inter layers were carried out, and the following conclusions can be obtained from the analysis results. 1) $\mathrm{Na}+\mathrm{Li}+, \mathrm{K}+, \mathrm{Ca} 2+$ based Montmorillonite structure was successfully built in Materials Studio software. Water absorption by Montmorillonite was simulated.

2) The results of molecular dynamics simulation show that the layer spacing and volume of montmorillonite increase as the number of adsorbed water molecules increases. Lattice constant $\beta$ is not changing monotonically with the increasing number of adsorbed water molecules. The simulation results reproduce the properties of the gradual expansion of the water absorption of montmorillonite in nature. 
3) Water molecules' concentration along z-axis shows the distribution of water during absorption process due to interaction with water and clay particles.

4) The results of radial distribution function show that $\mathrm{Li}+$ is more easy to hydrate, while $\mathrm{Na}+$ is the second, $\mathrm{K}+$ and $\mathrm{Ca} 2+$ are not easy to hydrate when located at the interlayer of Montmorillonite.

\section{ACKNOWLEDGEMENTS}

This research is funded by National Natural Science Foundation of China (No. 11672066). The authors are greatly appreciated.

\section{REFERENCES}

1) Abduljauwad, S. N. (2000): Laboratory and field studies of response of structures to heave of expansive clay, Geotechnique, 50(1), 197-198.

2) Auerbach, M. S., Carrado, A.K. and Dutta, K. P.(2004): Handbook of Layered Materials, CRC Press.

3) Bathija, P.A., Liang, H., Lu, N., Prasad, M., Batzle, L. M. (2009): Stressed swelling clay. Geophysics, 74(4), 47-52.10.1190 / 1.3131385.

4) Bishop, J., Murad, E. and Dyar. D. M. (2002): The influence of octahedral and tetrahedral cation substitution on the structure of smectites and serpentines as observed through infrared spectroscopy, Clay Minerals, 37 (4), 617-628.

5) Boek, S. E., Coveney, V. P. (1995): Molecular modeling of clay hydration: a study of hysteresis loops in the swelling curves of sodium Montmorillonite, Langmuir, 11, 4629-4631.

6) Chang, C., F-R., Skipper, T. N. and Sposito, G (1995): Simulation of interlayer molecular structure in sodium montomorillonite hydrates, Langmuir, 11(7), 2734-2741.

7) Chang, C., F-R., Skipper, T. N. and Sposito. G. (1997): Monte carlo and molecular dynamic simulations of interfacial structure in Lithium-montomorillonite hydrates, Langmuir, 13, 2074- 2082.

8) Chang, C., F-R., Skipper, T. N. and Sposito, G. (1998): Monte carlo and molecular dynamic simulations of electrical double-layer structure in potassium-montomorillonite hydrates, Langmuir, 14, 1201-1207.

9) Lennard-Jones, J. E. (1924): On the determination of molecular fields, Proc. R. Soc. Lond. A, 106 (738): 463-477.

10) Luckham, P. F. and Rossi, S. (1999): The colloidal and rheological properties of bentonite suspensions, Advances in
Colloid \& Interface Science, 82 (1-3), 43-92.

11) Na, P., Zhang, F. and Li, Y. (2006): Molecular dynamics simulation of Na-montmorillonite and $\mathrm{Na} / \mathrm{Mg}$-montmorillonite hydrates, Acta Physico-Chimica Sinica, 22(9), 1137-1142. DOI: 10.1016/S1872 -1508(06)60053-3.

12) Qi., S. and Vanapalli, K. S. (2016): Influence of swelling behavior on the stability of an infinite unsaturated expansive soil slope, Computers and Geotechnics, 76, 154-169.

13) Rappe, K. A., Casewit, J. C., Colwell, S. K., Goddard, III., A.W., Skiff, M.W. (1992): UFF, a full periodic table force field for molecular mechanics and molecular dynamics simulations, J. Am. Chem. Soc. 114, 10024-10035.

14) Skipper, N. T. (1995): Monte carlo simulation of interlayer molecular structure in swelling clay minerals. 2. Monolayer Hydrates, Clays \& Clay Minerals, 43 (3), 285-293.

15) Sun, L., Ling, Y., C., Lavikainen, P. L., Hirvi, T. J., Kasa, S. and Pakkanen, A. T. (2016): Influence of layer charge and charge location on the swelling pressure of dioctahedral smectites, Chemical Physics, 473, 40-45.

16) Van Geet, M., Volckaert, G., Bastiaens, W., Maes, N., Weetjens, E., Sillen, X., Vallejan, B. and Gens, A. (2007): Efficiency of a borehole seal by means of pre-compacted bentonite blocks, Physics \& Chemistry of the Earth, 32 (1), 123-134.

17) Ying, Z., Yuan, J. and Wei J. (2012): The influence of crack on the expansive soil slope, Geotechnical Engineering (Chinese), 34(12), 2155-2161.

18) Young, A. D., Smith, E. D. (2000): Simulations of clay mineral swelling and hydration: dependence upon interlayer ion size and charge, J. Phys. Chem. B 104, 9163-9170.

19) Zhao, X. (1980): Radius calculation of Cations, ACTA CHIMICA SINICA, 3, 11-16.

20) Zhuang, G., Zhang, Z., Fu, M., Ye, X. and Liao L. (2015): Comparative study on the use of cationic-nonionic-organomontmorillonite in oil-based drilling fluids, Applied Clay Science, s 116-117, 257-262. 